\title{
Spatial Interaction of Urban-Rural System and Influence Pattern in the Arid Inland River Basin - a Case Study in Shiyang River Basin in Northwest China
}

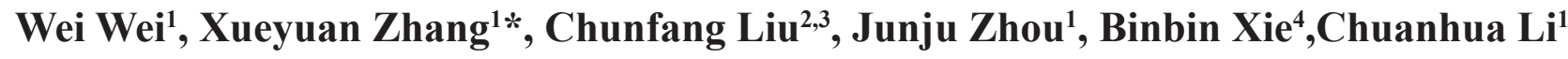 \\ ${ }^{1}$ College of Geography and Environmental Science, Northwest Normal University, Lanzhou 730070, Gansu, China \\ ${ }^{2}$ College of Social Development and Public Administration, Northwest Normal University, \\ Lanzhou 730070, Gansu, China \\ ${ }^{3}$ Gan Su Engineering Research Center of Land Utilization and Comprehension Consolidation, \\ Lanzhou 730070, Gansu, China \\ ${ }^{4}$ School of Urban Economics and Tourism Culture, Lanzhou City University, Lanzhou 730070, Gansu,
} China

Received: 4 August 2020

Accepted: 15 October 2020

\begin{abstract}
Different period remote sensing images of three years in 2000, 2010 and 2019 were selected as the data source, and the cost weighted distance model and urban-rural potential index were used to express the spatial connection. Besides, urban-rural expansion intensity index and urban-rural expansion speed index were also used to analyze urban and rural spatial structure of Shiyang River Basin. GIS technology combined with road grade and length was used to calculate the shortest time distance between urban and rural nods. Spatial association and interaction between urban and rural systems were analyzed through the time and distance, and the spatial structure changes and influential patterns of the Shiyang River Basin were discussed. The results showed that: (1) the urban-rural spatial expansion was dominated by central cities, the small towns had cluster distribution while the large towns were scattering. The urban-rural spatial structure system showed Jinchang, Wuwei city were the axis points, and Yongchang, GuLang, Minqin and Tianzhu are the axis line, which formed pointaxis structure and the "F" layout. (2) The pattern of city-county-town showed network development patterns, which indicated the influence of administration privilege to the spatial structure of urban-rural system. The key connection between the urban and rural area was road network but the administrative association was the dominated factor, especially inside of the whole river basin. (3) The administrative contact was much more than economic contact, management contact and information exchanges.
\end{abstract}

*e-mail: 714347818@qq.com 
The spatial structure and system formed a three-level management network pattern that was "city-county-small town" in Shiyang River Basin.

Keywords: spatial interaction, urban-rural system, Influence pattern, Shiyang River Basin

\section{Introduction}

As the indicator in the state of regional development, the urban-rural spatial structure is the function of the regional development, and the spatial clustering scale and form made by the socio-economic objects' spatial interaction [1,2], so it is of great significance to study the spatial interaction of urban-rural system for the urban-rural planning and the sustainable development. Urban-rural spatial structure pattern and their interaction determines the efficient use of natural resources and the sustainable development of social economy $[3,4]$.

As a social, economic and physical entity, city has the attractive and radiological function to the small city and towns which are located in its surroundings. The influential range of the city, namely the attraction of the city, refers to a region in which the attractive and radiological function of a city to its surrounding area play a dominant role in social economic ties, with a series of hierarchical nested, interlaced, excessive, competitive and varied characteristics [5-7]. The influential range of the town is an important indicator to judge the intensity of competition and the regional function, and it is also an important field in the research of urban spatial structure currently. At present, defining influential pattern of the city mainly has two kinds of method, including empirical and theoretical method [8-10]. Empirical method often collects data about personal, material, capital, information exchanges through actual investigation in different areas and cities, and then compare to associations and exchanges in all aspects of the regions and cities. The connection among different cities or towns are determined by connected frequency degree and exchange number [11, 12]. Finally, according to the connected frequency degree between small region and urban, the influence area is divided different sections, which is called the cities' influential and attractive range. However, using empirical method to divide attraction scope of the city needs to collect and select representative, high accuracy, easy to statistics and easily comparable indexes, which base on a large amount of statistical data [13]. At present, theoretical method is the main method of the influence between cities and urban-rural system, it is mainly based on the theory of spatial interaction, and the influence of the city on the surrounding area is proportional to the size of the city and inversely proportional to the distance to the city [14]. For example, breaking point model, field strength model and voronoi graph model are the primary models in the field.
At present, studies on the spatial structure and inter-connection turn to the dynamic analysis from the static description, and from qualitative speculation of spatial connection theories to large application of quantitative model. For the first time in 1942, G.K. Zipf [15] brought in the law of universal gravitation into the city system to analyze the urban spatial interaction, to have founded the theoretical basis for the urban-rural spatial interaction. From then on, the foundation of growth pole, spatial interaction theory, spatial diffusion theory and spatial connection model provided abundant theoretical basis for the study of spatial urban-rural interaction. The present study on spatial structure of the urban-rural system and influence pattern mainly includes the evolution of the urban-rural spatial structure, the formation of the spatial urban-rural system, the spatial organizing structure [16]. Since the 1990s, some scholars have greatly achieved on the study and illustration of urban and rural system theory, and some others analyze metropolitan circle through direct surveys about many social and economic association flow and the spatial reset of the related connecting strength as well as the economic spatial function of the city agglomerations with the model of measurement. The interrelationship of cities is indicated mainly by the urban flow model or the spatial urban interaction strength model.

However, the urban flow only reflects the outreach connection degree of the city itself, and the spatial strength of urban only reflects spatial influence degree between cities, the single evaluation cannot explain all the different degree of cities' connection [17]. Besides, most models now available haven't involved the influence of the natural condition of the inner city and the spatial connection [18].

This paper tries to analyze the spatial connective strength of urban-rural systems in Shiyang River Basin in arid China base on spatial interaction strength model and the urban-rural expansion index. The result can give making-decision support on the urban-rural sustainable development at the basin scale and the scientific reference on urban-rural development planning and managements. The objectives of the study are: (1) understand the spatial connection between the cities and small towns in arid inland at basin scale; (2) describe the spatial structure of urban-rural systems in arid inland, and (3) explore the spatial influence pattern among the cities, towns and rural system. 


\section{Material and Methods}

\section{Study Area}

The Shiyang River Basin (101 $22^{\prime}-104^{\circ} 16^{\prime} \mathrm{E}$ and $36^{\circ} 29^{\prime}-39^{\circ} 27^{\prime} \mathrm{N}$ ) is one of the three inland river basins in the Hexi corridor, lying in the east of the corridor, Gansu Province in northwestern China. The basin occupies an area of $4.16 \times 10^{4} \mathrm{~km}^{2}$ and includes seven counties $[19,20]$. The basin is located in continental temperate zone with arid climate and variable topography. The annual precipitation is $100-600 \mathrm{~mm}$, whereas the annual pan evaporation is $700-2,600 \mathrm{~mm}$. The Shiyang River originates from the Qilian Mountain with eight tributaries, which are mainly fed by rainfall, snowmelt and glacier melt in the Qilian Mountain. The total water resource is $16.61 \times 10^{8} \mathrm{~m}^{3}$, of which surface runoff is about $15.61 \times 10^{8} \mathrm{~m}^{3}$ and groundwater is $1.00 \times 10^{8} \mathrm{~m}^{3}$. The terrain of basin is high in south and low in north, and tilt from the southwest to northeast. Influenced by the climate, ecohydrology, landscape and other natural conditions, the soil and vegetation types of the basin form an obvious vertical spectrum of soilvegetation [21].

\section{Data Sources and Processing}

Landsat TM/ETM/OLI images in May, 2000, July, 2010 and May, 2019 were obtained from http://www. gscloud.cn/. All the pre-processed (e.g., geo-referenced, rectified and cropped pertaining) images were used to extract the urban and rural boundaries, the urban-rural system points, and a part of roads and streams. In the processing of extraction, Google Earth images were used to modify the boundary because of its higher resolution. The rural roads were obtained from topographic map $(1: 50,000)$ and Google Earth images. The data of main roads were got from digitization maps referred to diagram of China Highway and Urban-rural Public Road Chart Collection pressed by The Map Press of Shandong Province in 2018, which was 1:500,000 scale data of the streets network of West Gansu province. The data were converted to .shp format by Global Mapper procedures [22]. The economic, population, market and investment statistics data in 2000, 2010 and 2019 were acquired from Management Bureau of the Shiyang River Basin and statistical yearbook of Wuwei city which were the official publication of the authoritative data. The statistical data were used to calculate the potential index of urban-rural systems, and analyze urban-rural potential radiation.

\section{The Urban-Rural Spatial Interaction Analysis}

The physical concept was brought into the research to understand the urban-rural spatial structure, the influence scope of one city to another city or town was seen force field and the influence power. The formula is as follows:

$$
F_{i k}=\frac{Z_{i}}{D_{i k}^{2}}
$$

In the formula (1), $F_{i k}$ is the field strength between city/town $i$ and the city or town $k$, and $Z_{i}$ is comprehensive scale value of the city $i, D_{i k}$ is the distance from city $i$ to city $k$.

The model emphasizes the city's influence and radiation to the surroundings according to the inverse distance attenuation [23, 24]. In the model, the influence from urban-rural area on each point in the area didn't simply reduce with the spatial straight-line distance, but along the directions and routes of the minimum resistance. The points may receive different radiation because of the different resistance. In order to reflect the different resistance, the cost weighted distance was used to concept the factual distance and instead of the $D_{i k}$ in the Formula (1) and improved the theory of field strength model [25]. To calculate the cost weighted distance, the resistance aspect of Shiyang River Basin needs to be determined. In this paper, the resistance was calculated by the following formula:

$$
C_{k}=\sum_{j=1}^{n} W_{j} A_{j k}
$$

In formula (2), $C_{k}$ is the collected cost weighted resistance; while $A_{j k}$ is the resistance value of the $j$ resistance factor on the point $k$; and $W$ is the weight of resistance $j$, while $\mathrm{n}$ is the total sum of the factors.

The condition of topography and the transportation are the main factors that influence on the urban-rural radiation [26], so slope and road access degree were selected as the resistance factors that affect the urbanrural distribution. Firstly, the resistance value of slope can be calculated from digital elevation model (DEM) data using Three-Dimension Analysis in ArcGIS platform, and the results were reclassified ten levels according to the contribution of different grades to radiological barriers (Table 1). Secondly, the accessibility degree of road was measured by the minimum distance from each point to the main urban-rural road, the nearer to the road, the higher the accessibility degree (Table 1). To analyze different effects of different-level roads to the accessibility degree, the distance function of ArcGIS spatial analysis model was used to calculate the shortest straight-line distance between any point in the area to the neighbor railway, highway, national road and the provincial roads (Fig.1), which was used to express the transport accessibility degree, and then the resistance value was calculated [27]. Thirdly, the cost weighted distance in ArcGIS platform can be used to calculate the cost weighted distance between each point in a county to every urban-rural center, which was the $D_{i k}$ value. The influence range from town to road was calculated according to the amount of distribution of each town and road using the cost allocation model of ArcGIS10.2 (Fig. 2). 
Table 1. Categories of cost value from slope and road distance.

\begin{tabular}{|c|c|c|c|c|c|}
\hline Slope (\%) & Cost Value & Distance $(\mathrm{km})$ & Slope $(\%)$ & Cost Value & Distance $(\mathrm{km})$ \\
\hline $0-5$ & 1 & $0-0.2$ & $25-30$ & 6 & $2-2.5$ \\
\hline $5-10$ & 2 & $0.2-0.5$ & $30-35$ & 7 & $2.5-3.0$ \\
\hline $10-15$ & 3 & $0.5-1$ & $35-40$ & 8 & $3.0-3.5$ \\
\hline $15-20$ & 4 & $1-1.5$ & $40-45$ & 9 & $3.5-4.0$ \\
\hline $20-25$ & 5 & $1.5-2$ & $>45$ & 10 & $>4.0$ \\
\hline
\end{tabular}

\section{The Urban and Rural Potential Index}

The city scale is mainly reflected by indexes such as area, population, economic level etc. These indexes only reflect a city's development from the superficial phenomenon, and can't fully and truly measure a city's developing potential. A steady developing town and rural environment can promote employment and supply available products and service. Besides, a town or rural can not only keep its own sustainable development, but also drive others make a good progress in development. In order to roundly express the development of town and rural, we brought in potential index to replace the " $Z_{i}$ " that symbolizes the city's integrated scale in Formula (1). The town and rural potential was conveyed by some factors such as comprehensive economic, job employment, investment, population, medical conditions, municipal facilities and sustainable development. Comprehensive economic was an elementary feature of the urban-rural system, which contained some indexes such as Gross Domestic Product (GDP) and the third industry value to reflect the superficial economic development degree. However,

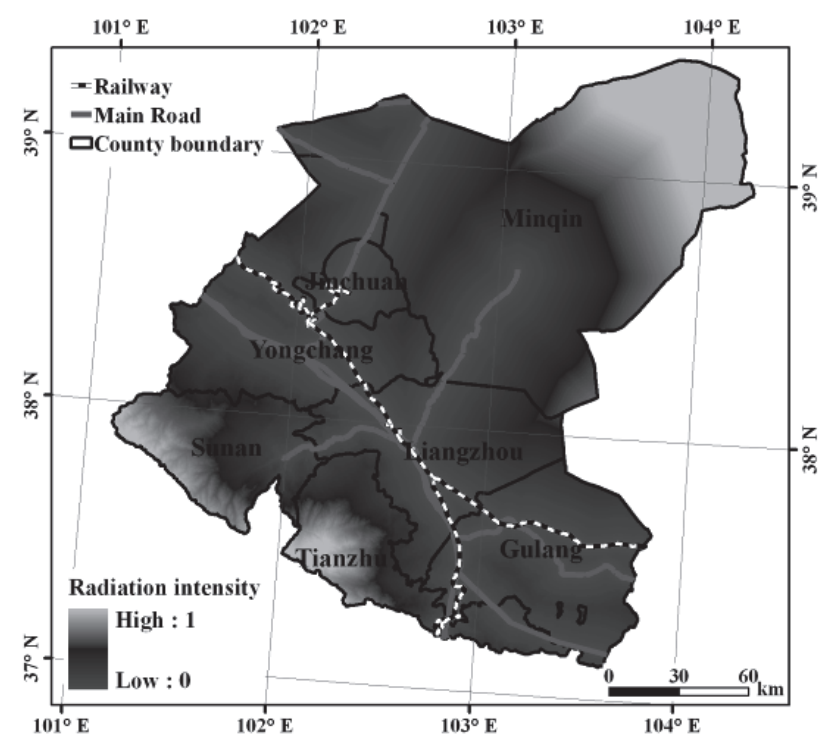

Fig. 1. Radiation intensity of each city and main road of the study area. Calculated the radiation of cities and main road, and then overlaid them together to get the figure. the economic developing situation cannot be easily measured only by comprehensive economic, so the job employment and the market factors are brought in to measure the economic development. At the same time, as an important support and indication for the economic development of an area, the factor of the investment was also used in the index system. In addition, the population was seen an important measurable index for the whole economic development level, and the medical service and the municipal construction were the guarantee for the current situation and the future urban and rural potential. So the study also brings in some indexes such as the non-agricultural population, the amount of the beds in the hospitals and the areas of the municipal construction were also used to reflect the $Z_{i}$. At last, 23 indexes were adopted to convey the urban and rural future developing potential in Table 2. The indexes are standardized variance and unified the order of magnitude. Then urban-rural potential index is calculated by weighting the equal value of twenty-three indexes. After getting the urban and rural potential index, the method of spline interpolation in ArcGIS platform was used to convert the potential index into grid chart (Fig. 3). According to the maximum value of

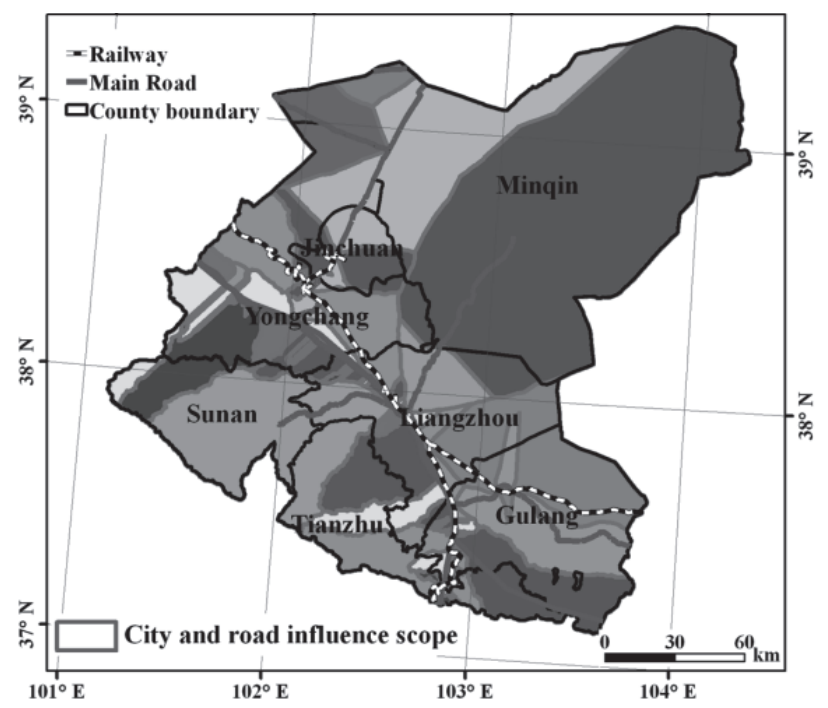

Fig. 2. Cities and roads influence scope. We calculated through cost allocation model in ArcGIS using each city and road, divided into several areas. 
Table 2 Indicator system of potential index.

\begin{tabular}{|c|c|}
\hline Measurement & Specific Indexes \\
\hline $\begin{array}{l}\text { Comprehensive } \\
\text { Economic }\end{array}$ & $\begin{array}{l}\text { Gross domestic product, the gross product of the first industry, the gross product of the second industry, } \\
\text { the gross product of the third industry }\end{array}$ \\
\hline Employment & $\begin{array}{c}\text { The amount of the employees, the average salary of the staffs, and the employment service agencies } \\
\text { amount }\end{array}$ \\
\hline Market & The size, the developing race, the area of the market \\
\hline Investment & $\begin{array}{c}\text { The investment for the fixed assets, the foreign investment contracted, the actual foreign investment } \\
\text { amount }\end{array}$ \\
\hline Population & Residents, non-farmers, the birth-rate, the natural rate of population growth \\
\hline Medical Affairs & The amount of the hospitals, the amount of the doctors, the amount of the beds \\
\hline Municipal Construction & The penetration rate of the gas, the total area of built-up, the area of the municipal building \\
\hline
\end{tabular}

index and the distance between urban-rural point and influence scope of city and road, the urban and rural potential influence scope is determined (Fig. 4).

\section{The Urban and Rural Expansion Intensity Index}

As an expansion intensity index, Iur is used to analyze and describe the expansion degree of all kinds of the urban-rural area, and to compare the strength, intensity, and the change trend of all kinds of city's built-up area [28]. The formula is showed as follows:

$$
I_{u r}=\frac{\Delta U_{i} \times 100}{T L A \times \Delta t}
$$

In Formula (3), $\Delta U_{i}$ is the amount of the urban-rural expansion during a certain period of time; $\Delta t$ is the time span of a certain period of time; TLA is the total area of the study target.

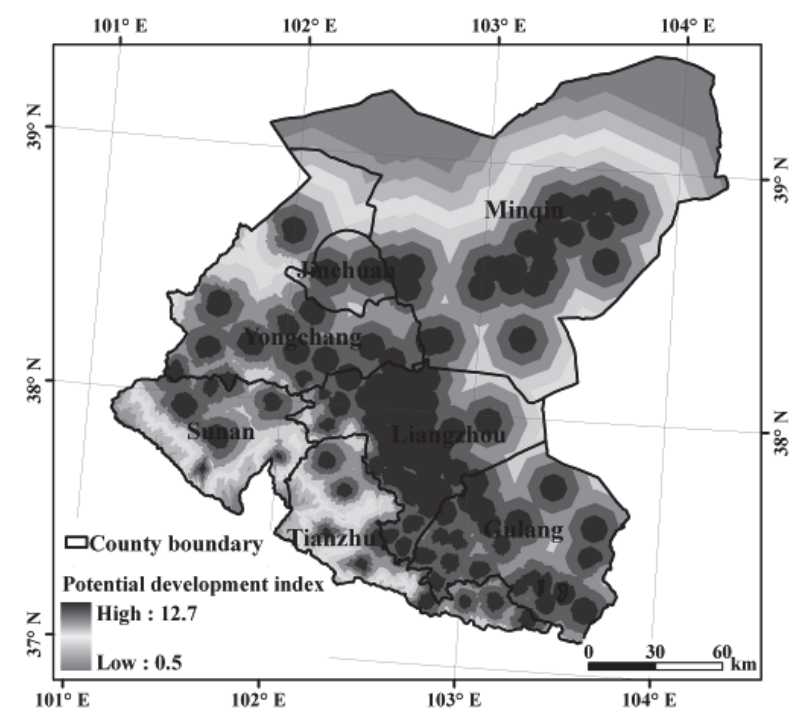

Fig. 3. Potential index distribution of each town.

\section{The Urban and Rural Expansion Rate Index}

In recent years, with the rapid development of the socio-economic in the Shiyang River Basin, the urban and rural are developing fast, which objectively make great influence to the change of the spatial structure and developing model of the inner basin. The urban and rural expansion rate index is used to express the development and expanding speed inner basin [29]. The formula is as follows:

$$
A G C=\frac{U A_{i+n}-U A_{i}}{n}
$$

In Formula (4), $U A_{i+n}$ represents the built-up area of urban-rural in the year $i+n, U A_{i}$ is the built-up area of urban-rural in the year $\mathrm{i}$, and $\mathrm{n}$ is the time, taking year as the unit.

The calculation above gets the intensity and the speed index of the urban-rural expansion during different time through the Microsoft Excel.

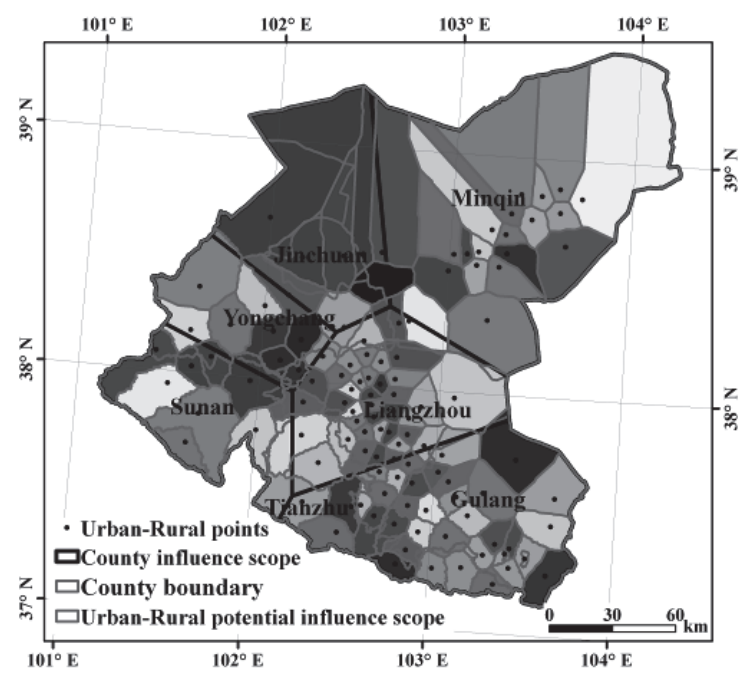

Fig. 4. Potential influence scope of urban-rural system. 


\section{Results}

The Urban-Rural Spatial Connection and Interaction in Shiyang River Basin

In Shiyang River Basin, the roads between the urban and rural district are connected by different
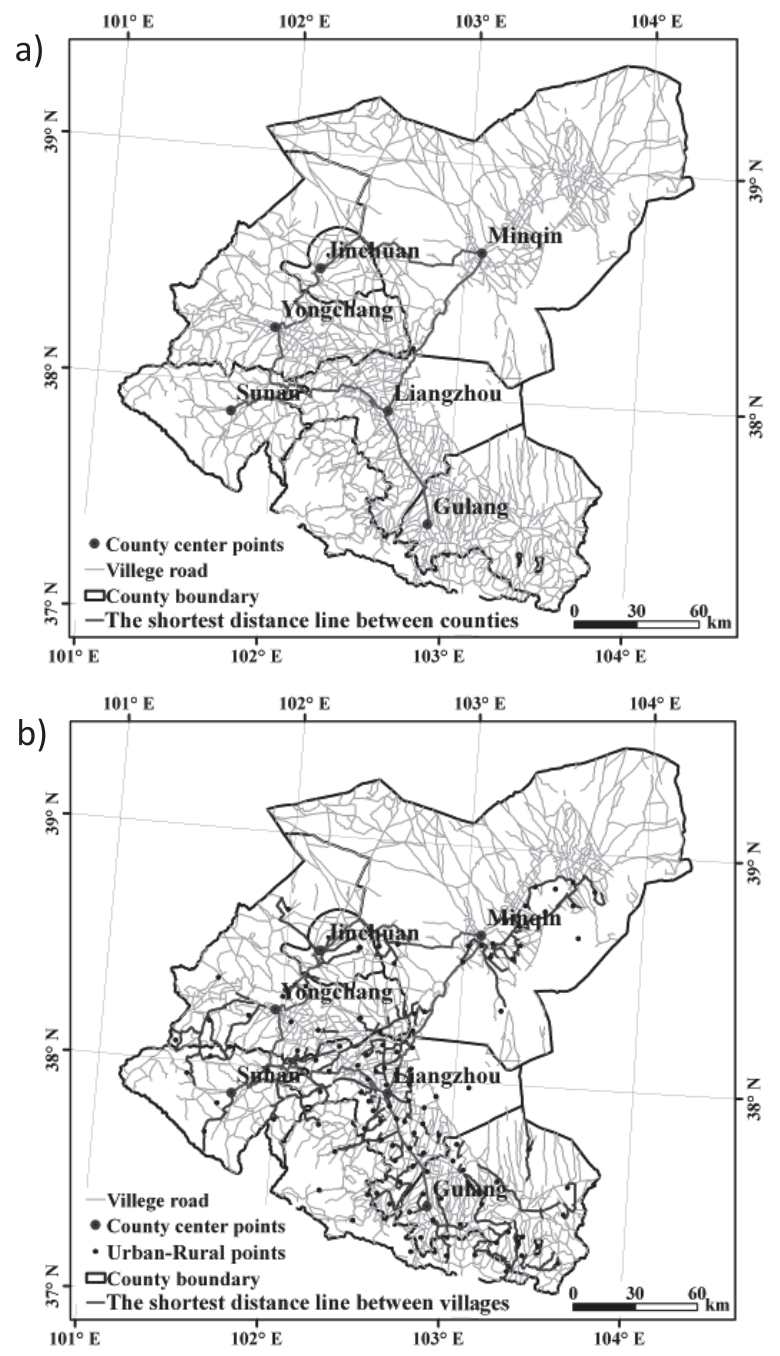

Fig. 5. The shortest time distance of urban-rural system. a) The shortest time distance between cities and towns and b) The shortest time distance between villages. levels. For the different combination of the differentleveled roads, the travel distance has very different in actual transport capacity. Therefore, the actual affection to people's travel is the time distance. In this paper, the actual travel time, that is the time distance, is used to measure the distance between the urban and rural area. The difference of the time distance and the spatial feature are used to analyze the spatial influence and inter-effects of the urban and rural area in the Shiyang River Basin. In the environment of ArcGIS, the road data group is built and the road system is generated, and all of the urban-rural points are mapped onto the road system points, on the system the shortest time distance calculated based on the analysis of the points between the urban-rural roads combination. In the process of the calculation of the urban and the rural gravitation, every urban-rural point is not only the start point but also the end point. The shortest time distance between urban and rural was calculated according to the different road level and different speed (highway: $100 \mathrm{~km} / \mathrm{h}$; national road: $70 \mathrm{~km} / \mathrm{h}$; provincial road: $50 \mathrm{~km} / \mathrm{h}$; township road: $30 \mathrm{~km} / \mathrm{h}$ ). The shortest time distance lines between urban and rural were determined (Fig. 5). The shortest time distance matrix among each urban is showed as Table 3.

The calculation shows that the difference is great of the urban and rural spatial connection in the Shiyang River Basin. The transport hub of the basin is mainly along the Liangzhou District and Jinchuan District, from those two places to other urban points have the most mature road system. The shortest time distance from Liangzhou District to Jinchuan District is 3.19 hours, while 3.08 hours to Minqin county.The shortest time distance is form Liangzhou District to Gulang county, which only 2.16 hours to the central, compared with the shortest time distance is 5.32 hours from Jinchuan District to Gulang county, which is the maximum. The minimum is only 1.84 hours which is from Jinchuan District to Yongchang county. For the location advantages in the basin, all central urban connection to the outside of basin is more intensive than inside of it. According to boundary of the administration, each city or town forms a closed system. The connection between the urban and rural district is mainly the transport systems, while the inner connection of each city or

Table 3. The shortest time distance matrix among each town (Unit: hour).

\begin{tabular}{|c|c|c|c|c|c|c|}
\hline & Yongchang & Su'nan & Jinchuan & Liangzhou & Minqin & Gulang \\
\hline Yongchang & 0 & 1.945 & 1.849 & 2.503 & 4.716 & 4.664 \\
\hline Su'nan & 1.945 & 0 & 3.398 & 3.306 & 6.027 & 5.468 \\
\hline Jinchuan & 1.849 & 3.398 & 0 & 3.192 & 3.49 & 5.324 \\
\hline Liangzhou & 2.503 & 3.306 & 3.192 & 0 & 3.087 & 2.167 \\
\hline Minqin & 4.716 & 6.027 & 3.49 & 3.087 & 0 & 5.219 \\
\hline Gulang & 4.664 & 5.468 & 5.324 & 2.167 & 5.219 & 0 \\
\hline
\end{tabular}




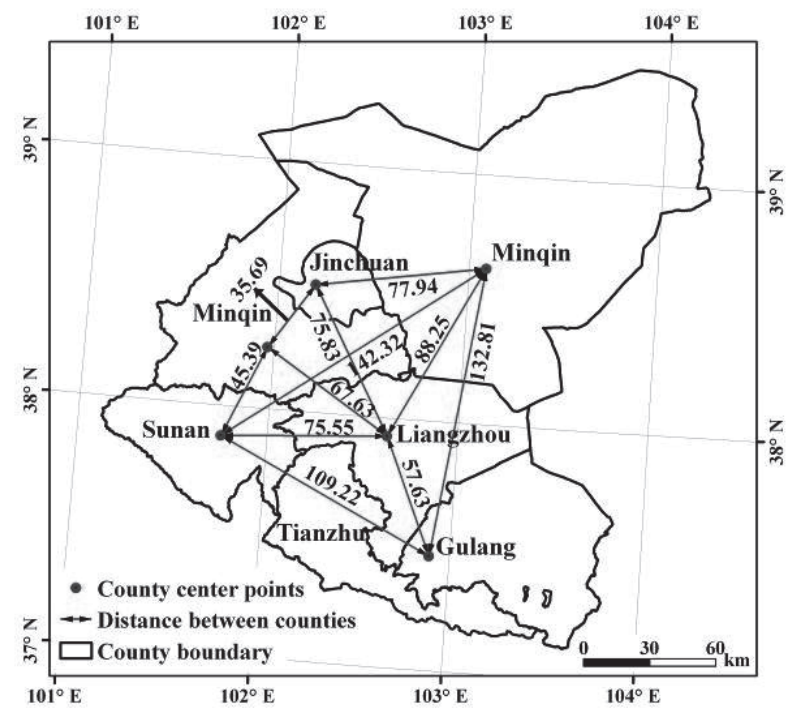

Fig. 6. The shortest linear distance among each town.

town is mainly the administrative network. From urban area to the rural area is connected through the highway, the national road, the provincial road and the township road.

\section{The Urban-Rural Spatial Influent Network}

With the help of ArcGIS10.4, six major city centers (the location point of government) are taken as the starting point to calculate the shortest linear distance among each town (Fig. 6) in order to analyze interrelationship and influent degree between the major towns. It was found that there are great differences in distance between large towns inside of the Shiyang River Basin. Among each town, there is a nearest distance from Jinchuan District to Minqin county, with the linear distance of $35.69 \mathrm{~km}$. Also there is a farthest distance from Sunan to Minqin county, with the distance of $142.32 \mathrm{~km}$. And the distance from the farthest to the nearest counties is as much as four times, the average linear distance between major towns also reached $82.58 \mathrm{~km}$. The spatial distance between the towns in Shiyang River Basin is much farther, especially in major cities and towns. The spatial influence network has not yet formed because of geographical isolation, the spatial extent of mutual communication and influence are limited.

\section{The Feature Analysis of the Spatial Structure}

Through the study, it is found that there is a special regional spatial structure in the Shiyang River Basin, which forms the distinctive and complete geographical units, and with the spatial pattern of "Small town, Multiple Center". Through the urban and rural

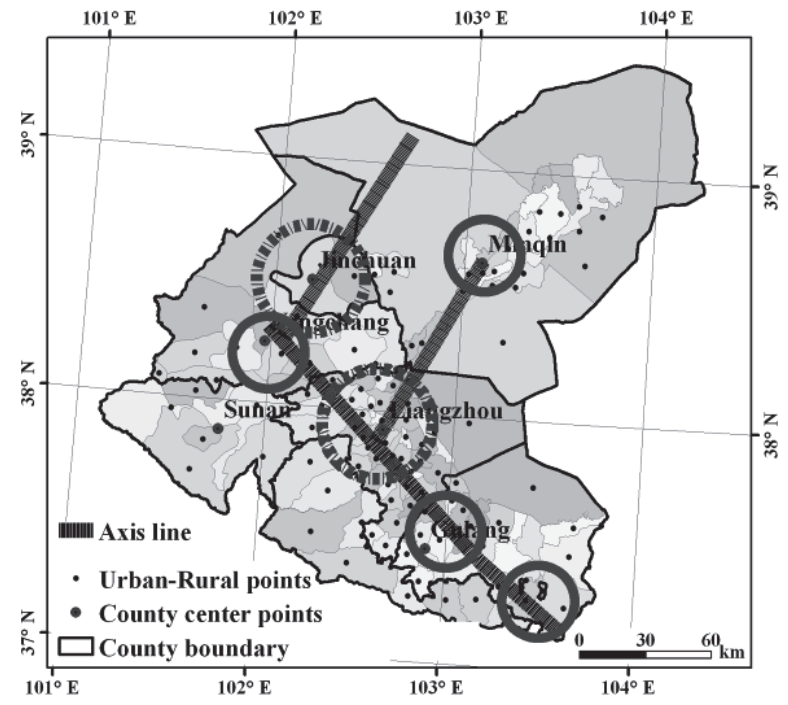

Fig. 7. Spatial structure of urban-rural system in Shiyang River Basin. The image display axis line and axis points (using circle to express, bigger circle is the high level city and smaller circle is the low level town).

interaction and the spatial distribution of the radiation intensity, it is found that the strongly spatial connected with each town in the basin mainly distributes around the national road G312 and along the line highway G30. The structure extends from Jinchuan District, Liangzhou District, Gulang county to Tianzhu county, which is shown by the main spatial combination of two-level "City-Town" influent region. Therefore, the spatial structure of urban-rural system inside of the basin is expressed as the structure of Point-Axis and shape of the "F" layout. Jinchang and Wuwei District as the axis point, while Yongchang county, Gulang county, Minqin county and Tianzhu county as its axis line (Fig. 7). Meanwhile, under the drive of administrative force of "Central City-County-Town", the structure appears the trend of the network-like development. The features of urban-rural structure in the basin appear as follows: (1) The regional level system of "Point-Axis" structure is composed of railway, highway, and national road and town points along these transport lines. This axis penetrates the whole basin from northwest to southeast and it is the mainly developed region, and accounts for $85 \%$ of towns and more than $90 \%$ of population. (2) The small-unit structure of the network system inside of the basin forms the axis points which contain small county and town. This kind of small unit structure makes the economic system by themselves, and it is closed comparatively. (3) The urban and rural development appears the characteristics of clustering towards Wuwei and Minqin county, the two pieces of main oasis which are also the important connection inside of the basin with the "Town-Water ResourcesOasis". 


\section{Discussion}

\section{The Influence Mode Analysis of the Urban and Rural System}

In the homogeneous condition of area, the edge of the urban-rural influent region appears as an Arc shape. However, with the influence of the topography and transport, the regions are of irregular shape and tend to expand to the direction of the low resistance. The different town-influenced regions are overlapped to form a different hierarchy system, and the high level influenced regions contain those of low level. According this rule, Shiyang River Basin can be divided into seven influenced area three different influenced levels. The first-level have two influenced areas which contain Minqin county and Jinchuan District. It has the largest area of $17,900 \mathrm{~km}^{2}$ and account for $43.03 \%$ of the whole area of the basin, and mainly influences by the road network, administration and the geographic characteristics. The secondary level influenced region has three influenced areas which contain Liangzhou District, Yongchang county and Su'nan county, and own an area of $19,800 \mathrm{~km}^{2}$, account for $47.43 \%$ of the whole area of the basin. Liangzhou District is the center that connects other influenced areas. The third level influenced region contain most of the middle and south part of the two counties called Gulang county and Tianzhu County, occupy the total area of $3900 \mathrm{~km}^{2}$, and account for $9.54 \%$ of the total area of the basin. In Shiyang River Basin, the agricultural ecological environment is quite weak and developing slowly, so it cannot enough support the urban-rural development of oasis, although its irrigated agriculture is quite advanced, what's more, all towns have mostly the same developing mode with the oasis and many small towns developing by themselves and much separately. After the survey in Shiyang River Basin, the level of urban and rural economic systems is very low and with a single economic structure. Towns communicate a little with the others of the same county, but little with the outer world in cultural background, economy and information. The urban-rural system has formed the conservative local culture for a long time.

\section{The Pattern Analysis of the Urban-Rural Expansion}

The urban-rural expansion intense index and rate index are used to analyze the change of the urbanrural system in recent years of Shiyang River Basin. The results show that the average intensity indexes in two periods from 2000 to 2005 and 2006 to 2010 are respectively 3.38 and 3.85.The county/county-level city has respectively the expansion intensity of 4.11 and 4.91, while the sub-level city or towns' are respectively 3.04 and 3.30. Through different periods of time, the central city is higher than the sub-level city and the urbanrural spatial expansion mainly take on the central city.
The average expansion rate in the different time (2000-2010 and 2010-2019) is respectively $22.24 \mathrm{hm}^{2} / \mathrm{a}$ and $25.61 \mathrm{hm}^{2} / \mathrm{a}$, while the sub-level cities are respectively $16.09 \mathrm{hm}^{2} / \mathrm{a}$ and $21.11 \mathrm{hm}^{2} / \mathrm{a}$. The central cities' expansion rate is obviously higher than the sublevel cities. During the years from 2000 to 2010, the area of the urban-rural built-up land has increased about $5.42 \%$ of the basin, and the expanded region mainly happened in Liangzhou District and Minqin county. Other place expanded a little. The area of high urban-rural spatial expansion rate is centered by the towns which have high urban-rural potential index such as Liangzhou District and Jinchuan District. The further from the central point, the lower the urban-rural expansion rate. Besides, in the process of the urban spatial expansion especially obvious in center city in Shiyang River Basin, the expanded characteristics obey the pattern "small aggregates, large dispersion", the gaps of cities and towns are becoming smaller and the space of urban land tends to be scattered.

\section{The Reason Analysis on Spatial Structure of the Urban-Rural System}

The urban-rural system of Shiyang River Basin appears to the characteristics of "small aggregates, large dispersion" in the $21^{\text {st }}$ century. Small aggregates mean the small towns and villages are becoming together and aggregated from 2000 to 2010 . There are several main reasons for this phenomenon, firstly, many roads and small commodity markets as well as farmer's market are built and repaired by the local government in the central area of the towns, which not only facilitate the daily life of the people and their production, but also make them move to near or central towns from the more distant villages. These can help them improve not only life quality but also time and cost savings of lives and production in their daily life. Secondly, the social investments are assimilated and education facilities such as elementary schools and kindergartens are built mainly by government, especially in remote mountainous areas, rural children and parents are moving to central area of the towns, where their children will receive a better education. Besides, due to the much more dispersed residences in poor mountains, under the guidance of government, most farmers move from a flatter and closer terrain to the villages and towns, so as to improve the support and management efficiencies of government. Large dispersion means the small towns and villages are becoming scattering and dispersed from 2000 to 2010 . There are several main reasons for this phenomenon.

\section{Conclusions}

Based on the theory of the spatial interaction, the concept of the cost-weighted distance and the urban-rural potential indexes are used to analyze the 
influent range and interaction between the cities and towns, which obviously reflects the spatial structure, connection and combination feature of the urban-rural area. The results showed that the spatial connection between urban and the rural was different in Shiyang River Basin. Liangzhou District and Jinchuan District was the central region and it was centered by the county with more interactive chances. The connection between urban and rural mainly depended on the transport systems, while the inner connection of each city or town mainly depended on administrative network. Urbanrural system was connected through highway, national road, provincial road and the township road. However, the connection of the technology, the information, the management is not enough, while the economic and information exchange is also very weak in the inner connection. The spatial structure of urban-rural system inside of the basin is expressed as the structure of Point-Axis and shape of the "F" layout. Jinchang and Liangzhou District as the axis point, while Yongchang county, Gulang county, Minqin county and Tianzhu county as its axis line.

\section{Acknowledgements}

We gratefully acknowledge the support by National Natural Science Foundation of China (grant numbers 41861040), Natural Science Foundation of Gansu Province (grant numbers 1506 RJZA129).

\section{Conflict of Interest}

The authors declare no conflict of interest.

\section{References}

1. BELL K.P., IRWIN E.G. Spatially explicit micro-level modelling of land use change at the rural-urban interface. Agricultural Economics. 27, 217, 2002.

2. HONG C., LIAO L.The interaction between the port and Kaohsiung city: Economy, institution and power. City, Culture and Society. 4, 21, 2013.

3. CHIAPPERO M.B., PANZETTA-DUTARI G.M. Contrasting genetic structure of urban and rural populations of the wild rodent Calomys musculinus (Cricetidae, Sigmodontinae). Mammalian Biology Zeitschrift für Säugetierkunde. 76, 41, 2011.

4. TANG Y., MASON R.J., SUN P. Interest distribution in the process of coordination of urban and rural construction land in China. Habitat International. 36, 388, 2011.

5. AMUSAN L.M., AKANYA C.N., ADEYEMO K.A., AYO C.K., MOHAMMED D.B. Renewal and Upgrading System For A Sustainable Urban-Rural Housing System Development: Panacea To Accommodation, Employment And Healthcare Issues. IOP Conference Series Earth and Environmental ence. 331, 12027, 2019.

6. TORNAGHI C., DEHAENE M. The prefigurative power of urban political agroecology: rethinking the urbanisms of agroecological transitions for food system transformation[J]. Journal of Sustainable Agriculture. 44, 594, 2020.

7. CASTRO A.V., DARIO P., LUPO S., CICCHINO A. C.Minimal stories in southeast buenos aires grasslands: carabid beetle biodiversity throughout an urban-rural gradient. Urban Ecosystems. 4, 1, 2019.

8. TANNIER C., THOMAS,I. Defining and characterizing urban boundaries: A fractal analysis of theoretical cities and Belgian cities. Computers, Environment and Urban Systems. 41, 234, 2013.

9. PAKER Y., YOM-TOV Y., ALON-MOZES T., BARNEA A. The effect of plant richness and urban garden structure on bird species richness, diversity and community structure. Landscape and Urban Planning. 122, 186, 2014.

10. PATINO J.E., DUQUE J.C. A review of regional science applications of satellite remote sensing in urban settings. Computers, Environment and Urban Systems. 37, 1, 2013.

11. PUERTAS O.L., HENRIQUEZ C., MEZA F.J. Assessing spatial dynamics of urban growth using an integrated land use model. Application in Santiago Metropolitan Area, 2010-2045. Land Use Policy. 38 ,415, 2014.

12. ALTIERI L., COCCHI D., PEZZI G., SCOTT E.M., VENTRUCCI M. Urban sprawl scatterplots for Urban Morphological Zones data. Ecological Indicators. 36, 315, 2014.

13. CHRISTIAENSEN L., TODO Y. Poverty Reduction During the Rural-Urban Transformation - The Role of the Missing Middle. World Development. 2014.

14. ZHANG J., ZOU H., WU Q., CHEN X. On the Spatial Organization of the Metropolitan Area. City Planning Review. 5, 19, 2001.

15. FERRARA A., SALVATI L., SABBI A., COLANTONI A. Soil resources, land cover changes and rural areas: Towards a spatial mismatch? Science of The Total Environment. 478, 116, 2014.

16. FORTUNATI L., TAIPALE S. Organization of the social sphere and typology of the residential setting: How the adoption of the mobile phone affects sociability in rural and urban locations. Technology in Society. 34, 33, 2012.

17. INOSTROZA L., BAUR R., CSAPLOVICS E. Urban sprawl and fragmentation in Latin America: A dynamic quantification and characterization of spatial patterns. Journal of Environmental Management. 115, 87, 2013.

18. SOMANJE A.N., MOHAN G., LOPES J., MENSAH A., TAKEUCHI K. Challenges and potential solutions for sustainable urban-rural linkages in a ghanaian context. Sustainability, 12, 507, 2020.

19. LANGENDIJK G.S., RECHID D., JACOB D. Urban areas and urban-rural contrasts under climate change: what does the euro-cordex ensemble tell us? - investigating near surface humidity in berlin and its surroundings. Atmosphere, 10, 730, 2019.

20. ASMA M., SYEDA B., MUHAMMAD C. Environmental quantification of the existing waste management system in a developing world municipality using easetech: the case of bahawalpur, pakistan. Sustainability, 10, 2424, 2018.

21. ZHANG Z., SU S., XIAO R., JIANG D., WU J. Identifying determinants of urban growth from a multiscale perspective: A case study of the urban agglomeration around Hangzhou Bay, China. Applied Geography. 45, 193, 2013.

22. MA J., PAN F., CHEN L., EDMUNDS W.M., DING Z., HE J., ZHOU K., HUANG T. Isotopic and geochemical 
evidence of recharge sources and water quality in the Quaternary aquifer beneath Jinchang city, NW China. Applied Geochemistry. 25, 996, 2010.

23. WEI W., SHI P., ZHOU J., FENG H., WANG X., WANG $X$. Environmental suitability evaluation for human settlements in an arid inland river basin: A case study of the Shiyang River Basin. Journal of Geographical Sciences. 23, 331, 2013.

24. WEI W., ZHAO J., WANG X., ZHOU Z., LI H. Landscape pattern MACRS analysis and the optimal utilization of Shiyang River Basin based on RS and GIS approach. Acta Ecologica Sinica. 29, 216, 2009.

25. TAUBENBOCK H., WIESNER M., FELBIER A., MARCONCINI M., ESCH T., DECH S. New dimensions of urban landscapes: The spatio-temporal evolution from a polynuclei area to a mega-region based on remote sensing data. Applied Geography. 47, 137, 2014.
26. SOHYLA R., ALIREZA Z.,SHAHRAM S., RAZIYEH T., TAN Y. Measures of spatial accessibility to health centers: investigating urban and rural disparities in kermanshah, iran. Journal of Public Health, 27, 519, 2018.

27. JIYOON P., SOLHEE K., KYO S. A comparative analysis of the environmental benefits of drone-based delivery services in urban and rural areas. Sustainability, 10, 888, 2018.

28. VEITCH J., SALMON J., BALL K., CRAWFORD D., TIMPERIO A. Do features of public open spaces vary between urban and rural areas? Preventive Medicine. 56, 107, 2013.

29. SALBACH N.M., O’BRIEN K., BROOKS D., IRVIN E., MARTINO R., TAKHAR P., CHAN S., HOWE J.A. Speed and Distance Requirements for Community Ambulation: A Systematic Review. Archives of Physical Medicine and Rehabilitation. 95, 117, 2014. 